\title{
Ex vivo and in vivo evaluation of an ultrasonic device for precise dissection, coagulation, and transection
}

This article was published in the following Dove Press journal:

Open Access Surgery

18 December 2014

Number of times this article has been viewed

\section{Brian D Bertke' \\ Patrick J Scoggins' \\ Alissa L Welling' \\ Tamara V Widenhouse ${ }^{1}$ \\ Chaoyang Chen ${ }^{2}$ \\ Srinivasu Kallakuri² \\ John M Cavanaugh ${ }^{2}$ \\ Jeffrey W Clymer' \\ Joseph F Amaral'}

'Ethicon, Inc., Cincinnati, $\mathrm{OH}$, USA; ${ }^{2}$ Spine Research Laboratory, Bioengineering Center, Wayne State University, Detroit, MI, USA
Correspondence: Jeffrey W Clymer

Ethicon, Inc., 4545 Creek Rd,

Cincinnati, OH 45242, USA

Tel +I 5 I3 3373318

Email jclymer@its.jnj.com
Background: A new ultrasonic device, Harmonic Focus ${ }^{\mathbb{Q}}+$, has been developed that is smaller and delivers energy more efficiently than its predecessor via the inclusion of Adaptive Tissue Technology. This study was undertaken to compare its dissection capabilities to an advanced bipolar electrosurgery device in benchtop and preclinical evaluations.

Methods: In ex vivo testing, Focus+ and LigaSure ${ }^{\text {TM }}$ Small Jaw were evaluated for physical dimensions, device and tissue temperature after repeated applications to porcine jejunum, and burst pressure of vessel seals, transection time, and tissue sticking in 3-5 mm porcine carotid arteries. In in vivo testing, the devices were tested on intact porcine carotid arteries for thermal damage via collagen denaturation and in muscle incisions near rat sciatic nerve for acute inflammation via hematoxylin and eosin and for impaired axonal transport via $\beta$-APP.

Results: Focus+ was smaller than the Small Jaw in width and height, yet it had a longer active blade and larger jaw aperture. Device temperatures were not different after application, but thermal spread (tissue temperature above $50^{\circ} \mathrm{C}$ ) was $78 \%$ greater for Small Jaw $(9.6 \mathrm{~mm})$ than for Focus+ $(5.4 \mathrm{~mm})$. Burst pressures of sealed vessels were not significantly different between the devices: $900( \pm 466) \mathrm{mmHg}$ for Focus+ versus $974( \pm 500) \mathrm{mmHg}$ for Small Jaw. Small Jaw had a shorter individual transection time (5.0 seconds compared to 6.3 seconds for Focus+), whereas Focus+ had $70 \%$ less tissue sticking. Thermal damage, neural inflammation, and impaired axonal transport were all significantly lower for Focus+ compared to Small Jaw, by $19 \%, 57 \%$, and $50 \%$, respectively.

Conclusion: With the addition of Adaptive Tissue Technology, Harmonic Focus+ builds upon the manifold advantages of ultrasonic devices in procedures requiring meticulous dissecting capability. Improvements in energy sensing and controlled delivery produce lower tissue temperatures and less thermal damage, especially critical when working near nerves. Focus + produces vessel seal strengths equivalent to advanced bipolar devices and, although individual device activations are longer, the reduction in tissue sticking is expected to materially lessen operative time in clinical practice.

Keywords: Harmonic, Focus, precision, vessel sealing, thyroidectomy, dissection

\section{Introduction}

Since their introduction at the end of the last millennium, ${ }^{1}$ ultrasonic devices have found rapid acceptance in surgical procedures that require precise dissection, efficient coagulation, and rapid transection. In comparison to electrosurgery, the mechanism of action of ultrasonic technology avoids the risk of electrical burns, reduces visual obstruction from smoke plumes, and induces less iatrogenic damage. ${ }^{2}$ Upon its introduction in 2008, Harmonic Focus ${ }^{\circledR}$, an ultrasonic shears device designed for open procedures, was quickly recognized as a safe and efficient method of dissection in surgery 
requiring meticulous hemostasis, such as thyroidectomy, and provided decreased operative time compared to an advanced bipolar device. ${ }^{3}$

When working near critical structures, such as nerves, smaller energy devices are naturally preferred, as long as speed and coagulative efficiency are not sacrificed. Harmonic Focus $^{\circledR}+$ Curved Shears (HAR9F; Ethicon Endo-Surgery, Inc., Cincinnati, OH, USA) have recently been modified from the previous version of the ultrasonic device to improve procedural efficiency in complex cases where careful dissection and frequent sealing are required. Harmonic Focus+ (Figure 1) has equivalent tissue indications compared to the prior device, such as the ability to seal vessels up to $5 \mathrm{~mm}$ in diameter, but has a $19 \%$ slimmer tip profile for more precision during dissection, while being 49\% faster in transection time. The new design also includes Adaptive Tissue Technology $^{4-6}$ that optimizes energy delivery. With this technology, the system has the ability to monitor the thermal state of the blade and identify conditions correlative to unnecessary thermal energy transfer, namely rapid increases in heat flux from the blade rubbing directly against the device pad rather than against the tissue itself. Since the tissue pad has no water content, temperature rises rapidly by frictional heating. As a result of the implementation of Adaptive Tissue Technology, Focus+ can transect tissue more quickly, while generating less heat at the blade and in the tissue.

There is always a concern with any energy device that heat generated by the device may injure tissue near the transection site, or that residual heat may cause damage via inadvertent contact with neighboring structures after transection is completed. This study was undertaken in order to compare the new Focus+ to LigaSure ${ }^{\mathrm{TM}}$ Small Jaw (LF1212A; Covidien, Mansfield, MA, USA), an advanced bipolar device, especially with regard to tissue damage produced at the site of surgery and the temperatures of the devices themselves after repeated usage. Ex vivo studies

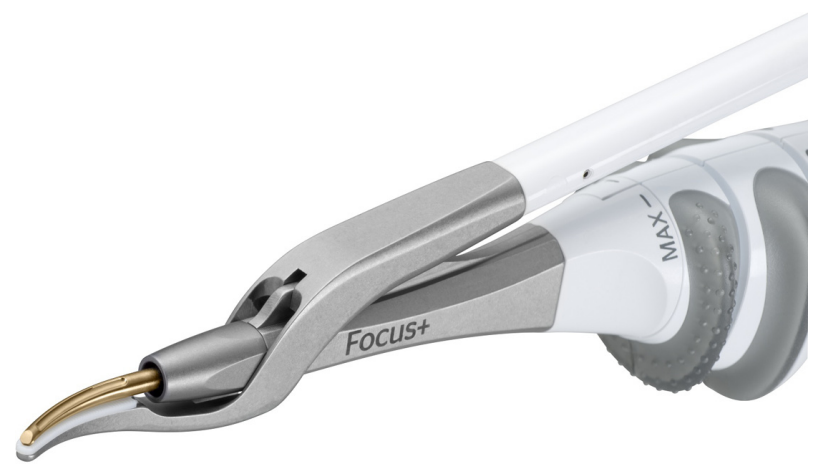

Figure I Harmonic Focus ${ }^{\circledR}+$ Curved Shears. measured the temperatures of the devices, spread of heat to tissue proximal to the transection site, and vessel sealing performance as assessed by burst pressure and tissue sticking. In vivo studies measured thermal damage assessed by collagen denaturation of sealed vessels and nerve damage assessed by levels of inflammation biomarkers. These endpoints were chosen to determine whether Focus+ is able to reduce the potential for thermal injury while maintaining its characteristic operative efficiency in hemostasis and vessel sealing strength.

\section{Methods}

The devices tested were the Harmonic Focus+ Curved Shears and the LigaSure Small Jaw Open Instrument. Focus+ was powered with the GEN11 generator at power level 3, and Small Jaw with ForceTriad ${ }^{\mathrm{TM}}$ Energy Platform (Covidien) at the default setting of two green bars.

\section{Ex vivo comparisons}

The two devices were compared by measuring with calipers the distal and proximal width of the clamp arm, the (closed) jaw height, the active blade width and length, and the (open) jaw aperture (Figure 2). Temperatures were measured using an A325 infrared thermal camera (FLIR Systems, Boston, MA, USA). Instrument temperature readings on the jaw and clamp arm of the device were taken after ten transections of porcine jejunum. Tissue temperature readings were made on porcine carotid artery segments that were attached at both ends to $50 \mathrm{~g}$ weights to provide tension to the vessel. Tissue temperatures were measured after 15 transections of the carotid arteries for each of ten Focus+ and ten Small Jaw devices. The thermally affected zone was defined as the total horizontal distance in which the tissue reached a temperature

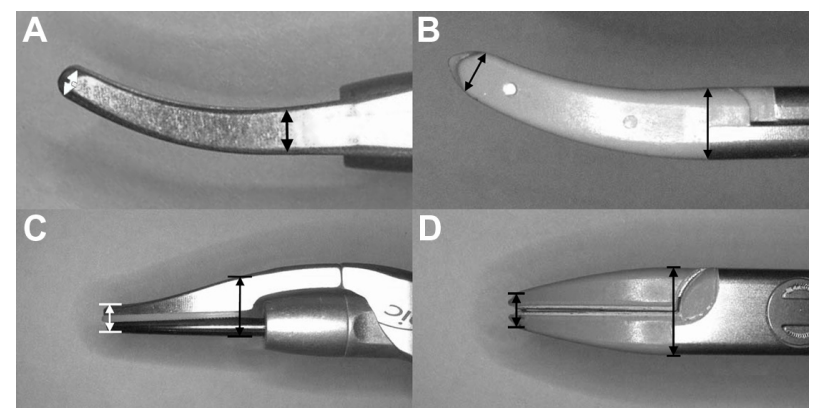

Figure 2 Dimensions measured for distal and proximal clamp arm widths and jaw heights.

Notes: (A) Harmonic Focus ${ }^{\circledR}+$ clamp arm width. (B) LigaSure $^{T M}$ Small Jaw clamp arm width. (C) Focus+ jaw height. (D) Small Jaw jaw height. For all measurements, the distal dimension is represented by the arrow on the left, and the proximal dimension by the arrow on the right. 
of $50^{\circ} \mathrm{C}$ or above. Based on the profile of the jaws of the Focus+ and Small Jaw devices, the thermally affected zone was divided into three categories of total, concave-side, and convex-side spread. Since all tissue within the jaw after activation of the devices was above $50^{\circ} \mathrm{C}$, the total thermally affected zone included the width of the jaw. However, when evaluating the concave and convex zones of the device, only the tissue outside of the jaw was taken into consideration.

For burst pressure measurements, porcine carotid arteries of 3-5 mm diameter were selected. Arteries are chosen for burst pressure testing because they experience higher pressures than veins in vivo. During sealing, the transection time was measured and each side of each device (concave, convex) was checked for tissue sticking. To measure the burst pressure, each side of the vessel seal was tested by filling with saline at a rate of $47 \mathrm{~mL} / \mathrm{min}$ and noting the pressure at which leakage occurred. For the calculations, the lower value of the pressure of the left and right side burst pressures was used.

\section{In vivo comparisons}

All procedures involving live animals were approved by the Ethicon or Wayne State University Institutional Animal Care and Use Committee. Thermal damage was assessed after sealing and transecting porcine carotid arteries that were $3-5 \mathrm{~mm}$ in outer diameter by measuring the extent of collagen denaturation via histological staining of the artery proximate to the transection with hematoxylin and eosin. ${ }^{5}$ For each seal, the top and bottom of each side of the seal was measured, with the maximum of the top and bottom values used in the analysis. The thermal footprint was calculated as the sum of the thermal damage on both sides of the jaw plus the proximal clamp arm width.

To determine the effect on nerve physiology, the devices were applied twice in rat lateral quadriceps muscle at a distance of $2 \mathrm{~mm}$ from the sciatic nerve, creating an incision $10 \mathrm{~mm}$ in length and approximately $5 \mathrm{~mm}$ in depth. ${ }^{7}$ Sections of the sciatic nerve were stained with hematoxylin and eosin to assess leukocyte infiltration and acute inflammation and with beta-amyloid precursor protein ( $\beta$-APP) antibody as a marker of impaired axonal transport. For both histological techniques, sections were examined as multiple high-power fields, and the presence or absence of the marker was recorded. The percentage of high-power fields with leukocyte infiltration or $\beta$-APP was used in the analysis.

\section{Statistical calculations}

Comparisons of continuous variables (eg, burst pressure) were performed using Student's $t$-test or the Mann-Whitney test, depending upon the nature of the distribution. For dichotomous variables (eg, tissue sticking), Fisher's exact test was used. A $P$-value of 0.05 or lower was considered to be significant.

\section{Results}

Harmonic Focus+ had a smaller clamp arm width, jaw height, and active blade width than LigaSure Small Jaw, at both distal and proximal locations (Table 1). For Small Jaw, the active blade width is the same as the clamp arm width, whereas, for Focus+, the active blade width is smaller than the total clamp arm width. Focus+ had a longer active blade length and larger jaw aperture than Small Jaw.

The mean temperatures at both the jaw and the clamp arm after ten transections were not significantly different between Focus+ and Small Jaw (Table 2). The test method had a $90 \%$ power to distinguish a difference of $3.6^{\circ} \mathrm{C}$ at the jaw and $1.4^{\circ} \mathrm{C}$ at the clamp arm. The median total thermal spread (ie, the extent of tissue temperatures $\geq 50^{\circ} \mathrm{C}$ ) for Focus+ was significantly less than that for Small Jaw (Figure 3 ). Both the concave- and convex-side mean thermal spreads were significantly less for Focus+ than for Small Jaw. The mean thermal spread on either side of Focus + jaw was less than $2.0 \mathrm{~mm}$.

There was no statistical difference between Focus+ and Small Jaw in burst pressures of sealed 3-5 mm porcine carotid arteries (Table 3 ). The test method had a $90 \%$ power to distinguish a difference of $254 \mathrm{mmHg}$. The median transection time for Small Jaw was shorter than for Focus+, whereas Focus+ had less tissue sticking than Small Jaw, both on the concave and convex sides of the devices. Overall, Small Jaw exhibited 3.4 times more sticking than Focus+.

Microscopic lateral thermal damage as assessed by collagen denaturation was greater for Small Jaw than for Focus+ (Table 4). The mean thermal damage for Focus+ was less than

Table I Sizes of Harmonic Focus ${ }^{\circledR}+$ and LigaSure ${ }^{T M}$ Small Jaw at relevant locations

\begin{tabular}{llll}
\hline Device site & $\begin{array}{l}\text { Harmonic } \\
\text { Focus+ }\end{array}$ & $\begin{array}{l}\text { LigaSure } \\
\text { Small Jaw }\end{array}$ & $\begin{array}{l}\text { Focus+l } \\
\text { LigaSure }\end{array}$ \\
\hline Clamp arm width, distal & $1.98 \mathrm{~mm}$ & $3.30 \mathrm{~mm}$ & $60.0 \%$ \\
Clamp arm width, proximal & $3.12 \mathrm{~mm}$ & $4.83 \mathrm{~mm}$ & $64.6 \%$ \\
Jaw height, distal & $2.82 \mathrm{~mm}$ & $3.61 \mathrm{~mm}$ & $78.1 \%$ \\
Jaw height, proximal & $5.99 \mathrm{~mm}$ & $8.86 \mathrm{~mm}$ & $67.6 \%$ \\
Active blade width, distal & $1.37 \mathrm{~mm}$ & $3.30 \mathrm{~mm}$ & $41.5 \%$ \\
Active blade width, proximal & $2.24 \mathrm{~mm}$ & $4.83 \mathrm{~mm}$ & $46.4 \%$ \\
Active blade length & $16.2 \mathrm{~mm}$ & $13.9 \mathrm{~mm}$ & $116.5 \%$ \\
Jaw aperture & $23.4 \mathrm{~mm}$ & $14.7 \mathrm{~mm}$ & $159.2 \%$ \\
\hline
\end{tabular}


Table 2 Ex vivo comparisons for mean ( \pm standard deviation) of device temperatures after repeated activation and thermal spread of temperatures $\geq 50^{\circ} \mathrm{C}$

\begin{tabular}{llll}
\hline Device site & $\begin{array}{l}\text { Harmonic } \\
\text { Focus }^{\circledR}+\end{array}$ & $\begin{array}{l}\text { LigaSure } \\
\text { Small Jaw }\end{array}$ & P-value \\
\hline Jaw temperature & $60.1^{\circ} \mathrm{C}\left( \pm 2.3^{\circ} \mathrm{C}\right)$ & $61.2^{\circ} \mathrm{C}\left( \pm 2.4^{\circ} \mathrm{C}\right)$ & $0.86 \mathrm{I}$ \\
Clamp arm temperature & $40.3^{\circ} \mathrm{C}\left( \pm 1.0^{\circ} \mathrm{C}\right)$ & $40.2^{\circ} \mathrm{C}\left( \pm 0.8^{\circ} \mathrm{C}\right)$ & 0.415 \\
Total thermal spread & $5.4 \mathrm{~mm}$ & $9.6 \mathrm{~mm}$ & $<0.00 \mathrm{I}$ \\
$\begin{array}{l}\text { Concave-side thermal } \\
\text { spread }\end{array}$ & $1.8( \pm 0.2) \mathrm{mm}$ & $3.2( \pm 0.4) \mathrm{mm}$ & $<0.00 \mathrm{I}$ \\
$\begin{array}{l}\text { Convex-side thermal } \\
\text { spread }\end{array}$ & $1.2( \pm 0.2) \mathrm{mm}$ & $2.4( \pm 0.2) \mathrm{mm}$ & $<0.00 \mathrm{I}$ \\
\hline
\end{tabular}

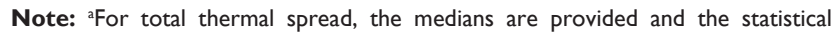
comparison was performed using the Mann-Whitney test.

$2.0 \mathrm{~mm}$. Lateral thermal footprint, which is the sum of the proximal clamp arm width and the thermal damage on both sides of the jaw, was greater for Small Jaw than for Focus+. Neural inflammation of sciatic nerve after application of the devices at a distance of $2 \mathrm{~mm}$ as assessed by leukocyte proliferation was greater for Small Jaw than for Focus+. Likewise, impaired axonal transport within the sciatic nerve as assessed by $\beta$-APP levels was greater for Small Jaw than for Focus+ (Figure 4).

\section{Discussion}

Harmonic Focus, the predecessor of Focus+, has been the subject of numerous studies in open surgical procedures where precise dissection and coagulation is required, such as head and neck procedures, mastectomy, peripheral vascular procedures, hepatectomy, pancreatectomy, and hemorrhoidectomy. For example, in the past year alone, Harmonic Focus has been shown to provide easy division of the renal isthmus without bleeding in the surgical repair of abdominal aortic aneurysm with coexistence of horseshoe kidney; ${ }^{8}$ easy dissection, enucleation, and excision in renal sparing surgery

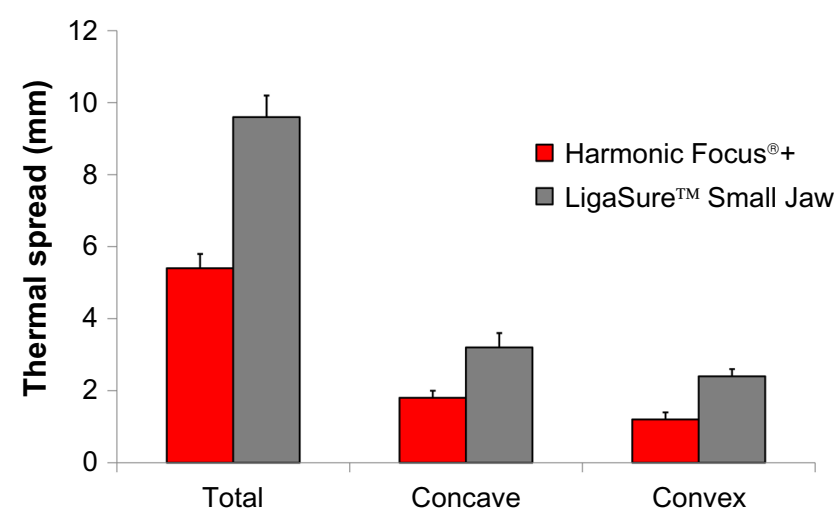

Figure 3 Thermal spread, where the temperature is $\geq 50^{\circ} \mathrm{C}$, for the total affected area and tissue on the concave and convex sides.

Note: Error bars represent the standard deviation.
Table 3 Ex vivo vessel sealing characteristics of devices in 3-5 mm porcine carotid arteries

\begin{tabular}{llll}
\hline $\begin{array}{l}\text { Sealing } \\
\text { measurement }\end{array}$ & $\begin{array}{l}\text { Harmonic } \\
\text { Focus }^{\circledR}+\end{array}$ & $\begin{array}{l}\text { LigaSure }^{\mathrm{TM}} \\
\text { Small Jaw }\end{array}$ & P-value \\
\hline $\begin{array}{l}\text { Tissue sticking: } \\
\text { concave side }\end{array}$ & $6 / 80(7.5 \%)$ & $\mathrm{I} / 777(19.5 \%)$ & 0.035 \\
$\begin{array}{l}\text { Tissue sticking: } \\
\text { convex side }\end{array}$ & $4 / 80(5.0 \%)$ & $\mathrm{I} / 777(23.4 \%)$ & $0.00 \mathrm{I}$ \\
$\begin{array}{l}\text { Transection time } \\
\text { Burst pressure }\end{array}$ & $\begin{array}{l}6.3 \mathrm{~s} \\
( \pm S D)\end{array}$ & $5.0 \mathrm{~s}$ & $<0.00 \mathrm{I}$ \\
\hline
\end{tabular}

Note: aFor transection time, the medians are provided and the statistical comparison was performed using the Mann-Whitney test.

of pediatric bilateral Wilms' tumor; ${ }^{9}$ a lowered incidence of postoperative wound complications compared to conventional electrosurgery during inguinal exposure in endovascular aortic aneurysm repair, ${ }^{10}$ a short period of time to secure the airway during tracheostomy; ${ }^{11}$ and a shorter operative time and reduced incidence of postoperative facial nerve paresis in superficial parotidectomy. ${ }^{12}$

Thyroidectomy, in which precision is especially important to avoid complications such as recurrent laryngeal nerve or parathyroid damage, is the most studied procedure in the literature for the use of Harmonic Focus, with over 30 randomized clinical trials comparing Focus to conventional procedures. ${ }^{13}$ Again in the past year, evaluation in thyroid surgery has shown that the use of Harmonic Focus provides shorter operative time; ${ }^{14-18}$ lower rates of hypocalcemia or hypoparathyroidism; ${ }^{14,15,19}$ shorter hospital stay; ${ }^{14,15}$ lower costs; ${ }^{16,18}$ and less blood loss. ${ }^{14}$ A recent network metaanalysis of thyroidectomy, in which most of the ultrasonic devices evaluated were Harmonic Focus, showed significantly faster operative time for the use of ultrasonic devices with no detriment to safety outcomes, such as nerve damage or parathyroid injury, compared to conventional surgery. ${ }^{13}$

Measurements made for this study show that Harmonic Focus+ is substantially smaller than Small Jaw both in clamp

Table 4 In vivo comparisons of mean ( \pm standard deviation) of thermal damage, thermal footprint, inflammation, and impaired axonal transport

\begin{tabular}{llll}
\hline Measurement & $\begin{array}{l}\text { Harmonic } \\
\text { Focus }^{\circledR}+\end{array}$ & $\begin{array}{l}\text { LigaSure }^{\mathrm{TM}} \\
\text { Small Jaw }\end{array}$ & P-value \\
\hline $\begin{array}{l}\text { Lateral thermal } \\
\text { damage }\end{array}$ & $\mathrm{I} .68( \pm 0.23) \mathrm{mm}$ & $2.07( \pm 0.39) \mathrm{mm}$ & 0.009 \\
$\begin{array}{l}\text { Lateral thermal } \\
\text { footprint }\end{array}$ & $6.47( \pm 0.35) \mathrm{mm}$ & $9.03( \pm 0.33) \mathrm{mm}$ & $<0.00 \mathrm{I}$ \\
$\begin{array}{l}\text { Neural inflammation } \\
\text { Impaired axonal }\end{array}$ & $\begin{array}{l}9.2 \%( \pm 5.4 \%) \\
\text { transport }\end{array}$ & $21.4 \%( \pm 3.7 \%)$ & 0.005 \\
\hline
\end{tabular}




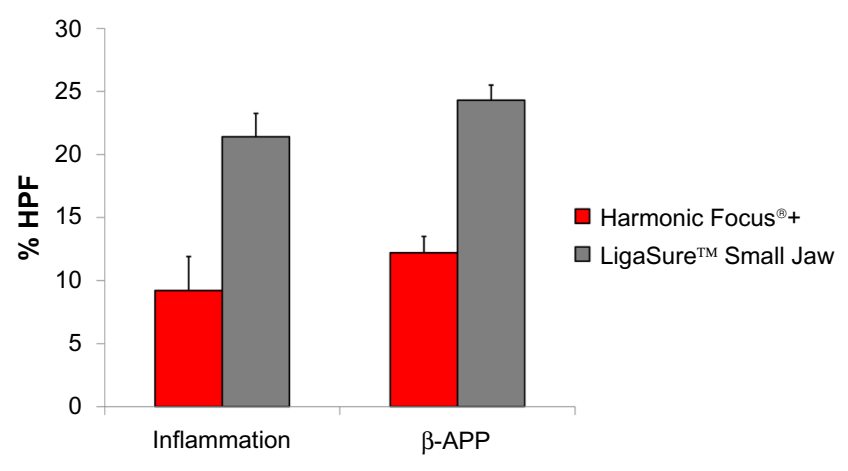

Figure 4 Percentage of high-power fields (HPF) with sciatic nerve inflammation and impaired axonal transport as assessed by $\beta$-APP after device application at a distance of $2 \mathrm{~mm}$.

Note: Error bars represent the standard error.

arm width and jaw height. Using the mean values for these dimensions and similar jaw lengths for both devices, the total volume of Focus+ end effector is less than half that of Small Jaw. This is critical in thyroid surgery where separation between the gland and superior laryngeal nerve or the parathyroids may be very narrow. More importantly for those procedures requiring the highest precision, the active blade width of Focus + is also less than half that of Small Jaw, even though the active blade length is $16 \%$ longer and the open jaw aperture is $59 \%$ greater. The smaller end effector of Focus+ enables the surgeon to more readily approach, seal, and cut a vessel at a perpendicular angle, which has been shown to provide a stronger seal..$^{20}$ The larger jaw aperture not only allows larger tissue bundles to be coagulated and transected, but also provides better dissecting ability by providing greater mechanical advantage of the dual-action jaw provided by the higher ratio of the handle size to the jaw size.

There is concern that, after repeated usage, an energy device can become hot and that inadvertent contact with the outside of the device might lead to tissue burns. Although the general perception is that an advanced bipolar device stays cooler than an ultrasonic one, in this study, neither the jaw nor clamp arm temperatures were significantly different between Focus+ and Small Jaw after repeated activations. In fact, the clamp arm temperature of Focus+ stayed well below $45^{\circ} \mathrm{C}$, the temperature at which long-term exposure can lead to changes in tissue structure. Despite this finding, it must be emphasized that meticulous surgical technique should be followed so that no critical structure is touched immediately after any energized device has been activated.

Ultrasonic and bipolar devices both heat tissue, but via different mechanisms. Ultrasonic energy heats tissue through the mechanical action of the blade with conduction of heat away from the blade. As a result, the tissue touching the blade is usually at the same temperature as the blade, while the surrounding tissue is cooler. In contrast, a bipolar device heats the surrounding tissue through Joule heating from the passage of electromagnetic radiation. Hence, the tissue surrounding the bipolar device can actually be hotter than the end effector itself. This effect is manifested in our results by the finding that, although device component temperatures were not different, Focus + exhibited significantly smaller thermal spread (ie, tissue temperature $\geq 50^{\circ} \mathrm{C}$ ) than Small Jaw.

The difference in thermal spread observed between devices is consistent with the results for thermal damage as assessed by collagen denaturation, where Focus+ produced significantly less thermal damage than Small Jaw. Likewise, the thermal footprint, consisting of the total thermal damage on both sides of the device together with the width of the device itself, was also significantly smaller for Focus+.

Both heat generation and the passage of electrical current are important when working in the vicinity of vital nerves. In contrast to bipolar tools, ultrasonic devices deliver no electrical current to the tissue. Since the heat generated by Focus+ at $2 \mathrm{~mm}$ from the blade is less than that produced by Small Jaw, it is not surprising that incisions made by Focus+ at this distance from the sciatic nerve exhibit lower levels of inflammation and impaired axonal transport than Small Jaw. These findings are consistent with a previous study, wherein we demonstrated less electrophysiological damage with an ultrasonic device than with electrosurgery, even though tissue temperatures were similar. ${ }^{7}$ Furthermore, the electrophysiological effects of the Harmonic blade used in the study were the same as those seen with sham surgery. These findings are also consistent with a large body of research that shows that Harmonic devices are similar to scissors in terms of tissue injury when used more than $2 \mathrm{~mm}$ from a nerve and activated continuously for less than 15 seconds. ${ }^{21-25}$

The decreased thermal damage induced by Focus + does not appear to come at the expense of seal strength. Using vessels of sizes that are commonly sealed in thyroid surgery, there was no statistical difference in mean burst pressures between Focus+ and Small Jaw, and both devices created seals with burst pressures that were more than seven times higher than normal physiological pressures. Individual transection time for Small Jaw was faster than for Focus+, as might be expected given the greater amount of thermal damage, but this speed advantage is likely compromised during actual use by the higher frequency of tissue sticking seen with Small Jaw. Focus+ exhibited 70\% less tissue sticking, a likely reason why, in clinical practice, ultrasonic shears were $22 \%$ faster than Small Jaw during sutureless thyroidectomy. ${ }^{17}$ Focus + has the additional advantage in comparison to Small Jaw of 
being able to cut all the way to the tip of the blade, providing enhanced dissection in difficult-to-access locations.

A limitation of this study is that it relies on benchtop and preclinical testing only. Although the superiority of Focus+ has been demonstrated in terms of its size, thermal spread, thermal damage, nerve effect, and tissue sticking in these tests, further study would be needed to fully understand its impact in clinical practice. However, as mentioned above, in a clinical setting, the previous version of Focus has been shown to be faster than Small Jaw. The current study also only evaluated the devices acutely, and it is unknown whether the observed advantage of decreased thermal damage from Focus + would persist during postoperative healing. Our previous studies have suggested that ultrasonic iatrogenic injury heals faster than electrosurgery incisions, ${ }^{26}$ and that this may be a result of lower levels of the inflammatory mediators produced after ultrasonic surgery. ${ }^{27,28}$ Future clinical evaluation will be necessary to determine whether Focus+ represents a substantial advance in real-world surgical procedures in which meticulous dissection and frequent coagulation are of paramount importance.

\section{Conclusion}

With the addition of Adaptive Tissue Technology, Harmonic Focus+ delivers improved dissecting capability compared to Ligasure Small Jaw, with less thermal damage and equivalent vessel seal strength.

\section{Disclosure}

This study was funded by Ethicon Inc, manufacturer of the Harmonic Focus+ shears. BDB, PJS, ALW, TVW, JWC, and JFA are employees of Ethicon Inc. The other authors report no conflicts of interest in this work.

\section{References}

1. Amaral JF. The experimental development of an ultrasonically activated scalpel for laparoscopic use. Surg Laparosc Endosc. 1994;4(2):92-99.

2. Amaral JF. Laparoscopic application of an ultrasonically activated scalpel. Gastrointest Endosc Clin NAm. 1993;3(2):381-391.

3. McNally MM, Agle SC, Williams RF, Pofahl WE. A comparison of two methods of hemostasis in thyroidectomy. Am Surg. 2009;75(11): 1073-1076.

4. Raghavan D, Howington JA, Broughton D, Henderson CE, Clymer JW. Comparison of two ultrasonic coagulating shears in sealing pulmonary vessels. Open Access Surgery. 2013;6:15-21.

5. Broughton D, Welling AL, Monroe EH, Pirozzi K, Schulte JB, Clymer JW. Tissue effects in vessel sealing and transection from an ultrasonic device with more intelligent control of energy delivery. Med Devices (Auckl). 2013;6:151-154.

6. Timm RW, Asher RM, Tellio KR, Welling AL, Clymer JW, Amaral JF. Sealing vessels up to $7 \mathrm{~mm}$ in diameter solely with ultrasonic technology. Med Devices (Auckl). 2014;7:263-271.

7. Chen C, Kallakuri S, Vedpathak A, et al. The effects of ultrasonic and electrosurgery devices on nerve physiology. Br J Neurosurg. 2012;26(6):856-863.
8. Chihara S, Fujino T, Matsuo H, Hidaka A. Surgical treatment of abdominal aortic aneurysm associated with horseshoe kidney: symphysiotomy using Harmonic Focus. Ann Thorac Cardiovasc Surg. Epub January 15, 2014.

9. Alkan M, Parlakgümüş C, Iskit SH, Tuncer R, Okur H, Zorludemir U. Renal sparing surgery using focus ultracision harmonic scalpel in patients with bilateral wilms' tumor: case report. Balkan Med J. 2013;30(3):318-320.

10. Santin BJ, Neville P, Recht M, Kuhn B, Muck P. Initial Experience with HARMONIC FOCUS ${ }^{\circledR}$ inguinal exposure in endovascular aortic aneurysm repair. Ann Vasc Surg. 2014;28(6):1416-1419.

11. Tsukahara K, Nakamura K, Motohashi R, Sato H, Suzuki M. Technique of Harmonic Focus ${ }^{\mathbb{E}}$ in tracheostomy. Otolaryngology. 2014;4(160).

12. Muhanna N, Peleq U, SchwartzY, Shaul H, Perez R, Sichel JY. Harmonic scalpel assisted superficial parotidectomy. Ann Otol Rhinol Laryngol. 2014;123(9):636-640.

13. Contin P, Gooßen K, Grummich K, et al. ENERgized vessel sealing systems versus CONventional hemostasis techniques in thyroid surgery - the ENERCON systematic review and network meta-analysis. Langenbecks Arch Surg. 2013;398(8):1039-1056.

14. Bangash A, Khan N, Azeem I, Sadiq M. Technique of clamp-tie thyroidectomy versus Harmonic Focus ${ }^{\mathrm{R}}$. Is there a need for technology? Journal of the Scientific Society. 2014;41:10-15.

15. Duan XF, Xue W, Zhu F, Sun DL. FOCUS harmonic scalpel compared to conventional haemostasis in open total thyroidectomy a prospective randomized study. J Otolaryngol Head Neck Surg. 2013;42:62

16. Lucchini R, Sanguinetti A, Monacelli M, et al. Health technology assessment and thyroid surgery. G Chir. 2013;34(7-8):198-201.

17. Teksoz S, Bukey Y, Ozcan M, Arikan AE, Ozyegin A. Sutureless thyroidectomy with energy-based devices: Cerrahpasa experience. Updates Surg. 2013;65(4):301-307.

18. Moreno P, Francos JM, García-Barrasa A, et al. [Efficacy and budget impact of the Focus harmonic scalpel compared to the ACS-14C device in total thyroidectomy due to multinodular goitre. A prospective randomised study]. Cir Esp. 2013;91(10):664-671. Spanish.

19. Pelizzo MR, Sorgato N, Isabella Merante Boschin I, Marzola MC, Colletti PM, Rubello D. Does the ultrasound dissector improve parathyroid gland preservation during surgery? Eur J Surg Oncol. 2014;40(7):865-868.

20. Voegele AC, Korvick DL, Gutierrez M, Clymer JW, Amaral JF. Perpendicular blood vessel seals are stronger than those made at an angle. J Laparoendosc Adv Surg Tech A. 2013;23(8):669-672.

21. Owaki T, Nakano S, Arimura K, Aikou T. The ultrasonic coagulating and cutting system injures nerve function. Endoscopy. 2002;34(7):575-579.

22. Carlander J, Johansson K, Lindström S, Velin AK, Jiang CH, Nordborg C. Comparison of experimental nerve injury caused by ultrasonically activated scalpel and electrosurgery. Br J Surg. 2005;92(6):772-777.

23. Jiang $\mathrm{H}$, Shen $\mathrm{H}$, Jiang $\mathrm{D}$, et al. Evaluating the safety of the Harmonic Scalpel around the recurrent laryngeal nerve. ANZ J Surg. 2010; 80(11):822-826.

24. Carlander J, Koch C, Brudin L, Nordborg C, Gimm O, Johansson K. Heat production, nerve function, and morphology following nerve close dissection with surgical instruments. World J Surg. 2012;36:1361-1367.

25. Lee KE, Jee HG, Kim HY, Park WS, Park SH, Youn YK. Development of a canine model for recurrent laryngeal injury by harmonic scalpel. Lab Anim Res. 2012;28(4):223-228.

26. Usas A, Usaite D, Gao X, Huard J, Clymer JW, Malaviya P. Use of an ultrasonic blade facilitates muscle repair after incision injury. J Surg Res. 2011;167:e177-e184.

27. Rubino LJ, Konstantakos EK, Stills HF Jr, Dudley ES, Grunden BK, Malaviya P. Healing of iatrogenic skeletal muscle wounds is affected by incision device. Surg Innov. 2010;17:85-91.

28. Nanduri B, Pendarvis K, Shack LA, et al. Ultrasonic incisions produce less inflammatory mediator response during early healing than electrosurgical incisions. PLoS One. 2013;8(9):e73032. 
Open Access Surgery

\section{Publish your work in this journal}

Open Access Surgery is an international, peer-reviewed, open access journal that focuses on all aspects of surgical procedures and interventions. Patient care around the peri-operative period and patient outcomes post surgery are key topics. All grades of surgery from minor cosmetic interventions to major surgical procedures are covered. Novel techniques

and the utilization of new instruments and materials, including implants and prostheses that optimize outcomes constitute major areas of interest. The manuscript management system is completely online and includes a very quick and fair peer-review system. Visit http://www.dovepress.com/ testimonials.php to read real quotes from published authors. 